\title{
DESAIN DAN MANUFAKTUR TABUNG GAS KOMPOSIT KARBON DENGAN METODE WET BLADDER COMPRESSION MOULDING
}

\author{
Aditya Nugraha \\ Program Studi Magister Teknik Mesin \\ Departemen Teknik Mesin dan Industri, \\ Fakultas Teknik, Universitas Gadjah Mada \\ Yogyakarta 55281, Indonesia \\ aditnyo2_atmi35@mail.ugm.ac.id
}

\author{
Gesang Nugroho *) \\ Departemen Teknik Mesin dan Industri, \\ Fakultas Teknik, Universitas Gadjah Mada \\ Yogyakarta 55281, Indonesia \\ gesangnugroho@ugm.ac.id \\ ${ }^{*}$ corresponding author
}

\begin{abstract}
ABSTRAK
Penggunaan material komposit semakin beragam seiring dengan kemajuan teknologi di berbagai bidang. Serat karbon merupakan material komposit yang banyak digunakan karena memiliki sifat mekanik yang baik, tahan korosi, memiliki rasio kekuatan terhadap berat jenis yang tinggi. Salah satu aplikasi penggunaan material komposit serat karbon yang sangat terbuka peluang pengembangannya adalah untuk tabung gas. Penelitian ini menyampaikan desain, proses manufaktur, dan pengujian tabung gas komposit. Proses desain meliputi desain tabung gas komposit, desain cetakan, dan desain bladder. Tabung gas komposit terbuat dari serat karbon dan matriks resin epoxy sebanyak enam lapis pada dinding tabung. Proses manufaktur dilakukan dengan metode wet bladder compression moulding yaitu dengan menggunakan dua buah mould dari material fiberglass bagian atas dan bawah, dan dengan menggunakan bladder atau kantung bertekanan dari latex untuk menekan material komposit. Uji hidrostatis dilakukan menggunakan manual test pump untuk menguji kekuatan tabung. Hasil pengujian menunjukkan tabung gas komposit serat karbon dapat menahan tekanan hidrostatis hingga 18 bar.
\end{abstract}

Kata kunci: bladder compression moulding, tabung gas, serat karbon.

\section{PENDAHULUAN}

Material komposit merupakan material dengan dua atau lebih komponen penyusun, dimana komponen penyusunnya memiliki sifat fisik atau sifat kimia yang berbeda, pengembangan material komposit telah memperkaya sistem material modern, berkontribusi pada kemajuan berkelanjutan dalam ilmu dan teknik material, serta bermanfaat bagi kehidupan manusia [1]. Data persentase bahan bakar utama rumah tangga untuk memasak dari Badan Pusat Statistik (BPS) pada tahun 2016 menunjukkan bahwa gas atau LPG (Liquefied Petroleum Gas) adalah bahan bakar yang paling banyak digunakan untuk memasak yaitu sebesar $72,38 \%$ dibandingkan dengan bahan bakar yang lain [2]. Dengan persentase kebutuhan bahan bakar gas yang sangat tinggi, tentu juga membutuhkan jumlah tabung gas yang sangat banyak pula, mengingat jumlah penduduk Indonesia yang mencapai 268 juta jiwa pada tahun 2020. Tabung gas LPG yang dipakai di masyarkat sekarang ini, sebagian besar berasal dari bahan logam. Material komposit karbon memiliki sifat mekanik yang baik, tahan korosi, memiliki rasio kekuatan terhadap berat jenis yang tinggi menjadikannya salah satu alternatif pengganti tabung gas dari logam. Tabung gas dari material komposit karbon aman untuk digunakan karena sifat dari komposit yang akan meleleh dan hancur pada temperatur tinggi yang ekstrem, didahului dengan proses keluarnya gas, sehingga meminimalkan terjadinya ledakan seperti pada tabung gas dari metal.

Secara umum, proses pembuatan material komposit dilakukan dengan memadukan filler atau material penguat dan matrik sebagai material pengikatnya [3]. Salah satu metode yang dapat digunakan untuk proses manufaktur material komposit adalah bladder compression moulding, metode ini menggunakan dua buah mould atau cetakan, yaitu cetakan bagian atas dan bawah, dan dengan menggunakan bladder atau kantong bertekanan. Bladder berfungsi memberikan tekanan pada bahan-bahan pembentuk komposit agar dapat menyatu dengan baik dan memiliki bentuk yang baik sesuai cetakan. Cetakan bagian atas dan bawah berbentuk negatif dari produk, sedangkan bladder berbentuk positif dari produk. Metode wet bladder compression moulding untuk penelitian ini adalah gabungan dari metode hand lay up pada saat proses fabrikasi tabung gas komposit, di mana resin dioleskan secara manual pada serat karbon, dan metode bladder compression moulding pada saat proses curing atau proses terjadinya reaksi kimia. Temperatur yang digunakan pada proses curing pada penelitian ini adalah temperatur ruangan.

Penelitian rancang bangun tabung komposit yang pernah dilakukan adalah rancang bangun tabung komposit tekanan tinggi atau composite overwrapped pressure vessel (COPV) untuk memperkecil berat struktur tabung propelan wahana roket cair. Penelitian dilakukan dengan 
melapisi tabung liner yang terbuat dari material stainless steel SS304 dengan serat karbon dan resin epoxy EPR 174 secara manual dengan metode hand lay up. Hasil pengujian menunjukkan bahwa tabung komposit tersebut dapat menahan tekanan statis hingga 200 bar, namun masih ada sedikit kebocoran [4]. Penelitian tentang kekuatan tarik produk komposit yang terbuat dari serat karbon dengan matriks resin epoxy yang dibuat dengan metode bladder compression molding (BCM) beserta proses manufaktur pembentukan komposit telah dilakukan, yaitu membandingkan material komposit hasil metode BCM dengan material penyusun yang sama, terhadap metode vacuum bagging dan hand lay-up. Pembentukan komposit serat karbon dengan metode BCM menghasilkan kekuatan tarik yang lebih tinggi dibanding dengan pembentukan komposit serat karbon dengan metode vacuum bagging. Proses pembentukan dengan metode BCM mampu meningkatkan kekuatan tarik sebesar $17,48 \%$ dari metode vacuum bagging yang kekuatan tariknya sebesar $515 \mathrm{MPa}$ [5].

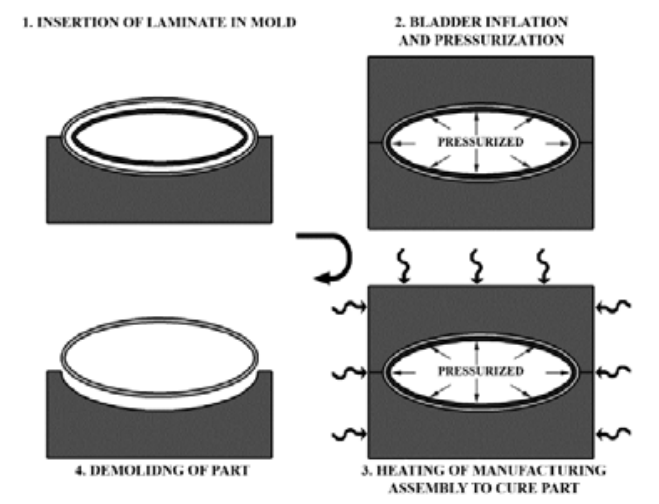

Gambar 1. Metode bladder compression molding [6].

Rumusan masalah dalam penelitian ini adalah bagaimana desain tabung gas dengan material komposit serat karbon, bagaimana proses manufaktur tabung gas komposit dengan menggunakan metode wet bladder compression moulding, dan bagaimana kekuatan tabung gas komposit terhadap tekanan hidrostatis.

Tujuan dari penelitian ini adalah membuat desain tabung gas dari bahan komposit dengan tekanan kerja 10 bar, melakukan proses manufaktur tabung gas komposit dengan material serat karbon jenis woven dengan matriks resin epoxy tipe Bisphenol A-Epichlorohydrin dan hardener EPH 555 tipe Cycloalipathic Anine dengan metode wet bladder compression moulding, dan menguji ketahanan tabung gas komposit terhadap tekanan hidrostatis.

\section{METODE}

Tahapan proses yang dilakukan dalam penelitian ini dinyatakan dengan sebuah diagram seperti pada Gambar 2.

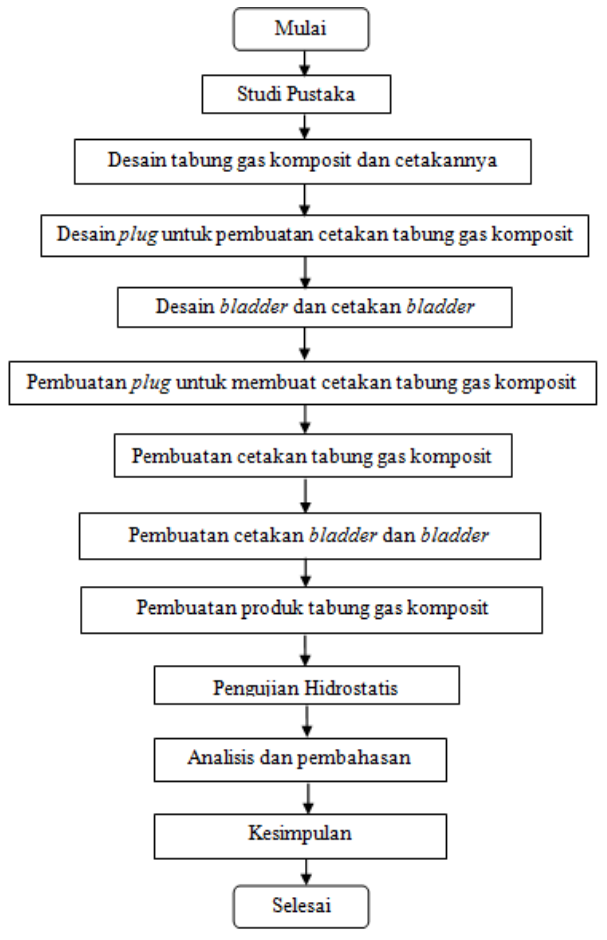

Gambar 2. Diagram alir penelitian.

Proses penelitian dilakukan melalui tiga tahap, yaitu proses desain, manufaktur dan pengujian.

\section{Proses Desain}

Proses desain dimulai dengan menentukan design requirements and objectives (DRO) dari tabung gas komposit. DRO didapatkan dari studi pustaka dan benchmarking dari tabung gas yang sudah ada. Berdasarkan Keputusan Direktur Jenderal Minyak Gas dan Bumi Kementrian Energi dan Sumber Daya Mineral Republik Indonesia Nomor 116.K/10/DJM/2020 tentang standar dan mutu (spesifikasi) bahan bakar gas LPG yang dipasarkan di dalam negeri, tekanan maksimum gas LPG yang diperbolehkan adalah 145 psig atau 10 bar pada suhu $100^{\circ}$ Fahrenheit atau $37.8^{\circ}$ Celcius [7], maka ditentukan tekanan operasi tabung gas komposit karbon sebesar 10 bar. Sedangkan referensi bentuk dan dimensi tabung gas komposit diambil dari tabung blue gas T911dengan dimensi tabung diameter $245 \mathrm{~mm}$ dan tinggi $436 \mathrm{~mm}$ [8], maka ditentukan dimensi tabung gas komposit yang akan dibuat dengan diameter $230 \mathrm{~mm}$ dan tinggi $300 \mathrm{~mm}$. 
Tabel 1. Design requirements and objectives tabung gas komposit

\begin{tabular}{l|c|l}
\hline \multicolumn{1}{c|}{ Spesifikasi } & Requirements & \multicolumn{2}{|c}{ Keterangan } \\
\hline $\begin{array}{l}\text { Tekanan } \\
\text { operasi }\end{array}$ & $10 \mathrm{bar}$ & $\begin{array}{l}\text { Tekanan kerja } \\
\text { maksimal gas } \\
\text { LPG }\end{array}$ \\
\hline $\begin{array}{l}\text { Tekanan } \\
\text { pengujian }\end{array}$ & $15 \mathrm{bar}$ & $\begin{array}{l}\text { Tekanan untuk } \\
\text { pengujian } \\
\text { hidrostatis }\end{array}$ \\
\hline Berat tabung & $<5 \mathrm{~kg}$ & $\begin{array}{l}\text { Berat maksimal } \\
\text { tabung dan } \\
\text { bagian-bagiannya }\end{array}$ \\
\hline $\begin{array}{l}\text { Kapasitas } \\
\text { tabung }\end{array}$ & $>11$ liter & $\begin{array}{l}\text { Kapasitas } \\
\text { minimal tabung }\end{array}$ \\
\hline $\begin{array}{l}\text { Diameter } \\
\text { tabung }\end{array}$ & $230 \mathrm{~mm}$ & \\
\hline Tinggi tabung & $300 \mathrm{~mm}$ & \\
\hline
\end{tabular}

Proses selanjutnya adalah penentuan ketebalan dinding tabung dengan menggunakan persamaan berikut [9]:

$$
\begin{gathered}
t=2.5 \times \sqrt{\frac{D i}{R m}} \\
t=2.5 \times \sqrt{\frac{220}{579}}
\end{gathered}
$$

dimana $D i$ adalah diameter dalam tabung $(\mathrm{mm})$ dan $R m$ adalah Tensile Strength material komposit karbon (MPa). Didapatkan hasil $t=1,54 \mathrm{~mm}$.

$$
\begin{aligned}
& t s=t+C A \\
& t s=1,54+0,5=2,04 \mathrm{~mm}
\end{aligned}
$$

dimana ts adalah tebal shell (mm) dan CA adalah Corrosion Allowance (mm). Perhitungan CA didapatkan dari pendekatan desain yaitu perhitungan masa pakai dikalikan dengan laju korosi per tahun. Diasumsikan tabung gas komposit akan digunakan selama 10 tahun, dengan laju korosi pertahun sebesar $0,05 \mathrm{~mm}$ maka didapatkan $C A$ total sebesar $0,5 \mathrm{~mm}$. Selanjutnya didapatkan ts $=2,04 \mathrm{~mm}$. Tebal shell minimal (ts) ditentukan sebesar 2,1 mm yaitu sebanyak enam lapisan komposit.

Desain tabung gas komposit dibagi menjadi empat bagian, yaitu tabung gas komposit bagian atas, bagian bawah, flange, dan head (Gambar 3). Flange terbuat dari material baja MS, dengan menggunakan sistem jepit diantara dua lapisan komposit. Flange dan head dikunci dengan lima buah baut M5. Tabung gas komposit dibuat dari material serat karbon jenis woven dengan matriks bisphenol A dan hardener. Tinggi tabung $300 \mathrm{~mm}$, dengan diameter tabung $230 \mathrm{~mm}$, dengan sambungan pada bagian tengah tabung secara horisontal.
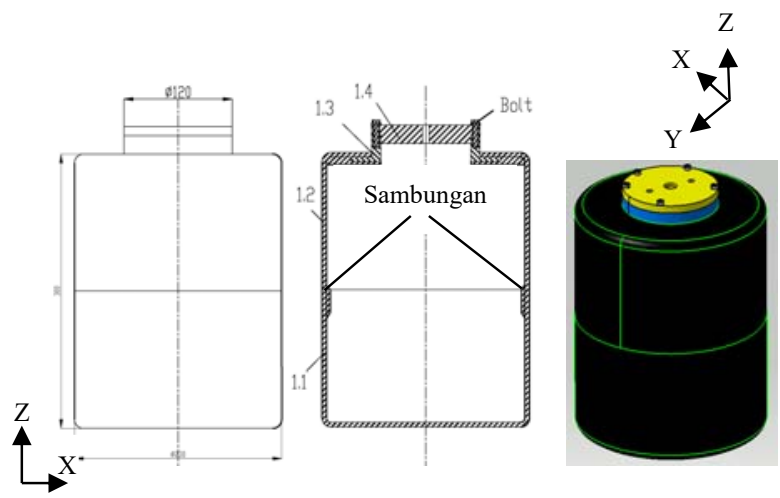

Gambar 3. Desain tabung gas komposit.

Cetakan yang dibuat berupa cetakan negatif yang dibagi menjadi empat bagian, yaitu dua cetakan bagian atas dan dua cetakan bagian bawah sesuai dengan model yang telah dibuat. Cetakan dibagi menjadi empat bagian untuk mempermudah pelepasan produk setelah proses pencetakan komposit. Sistem pencekaman dengan menggunakan 51 buah baut M10.

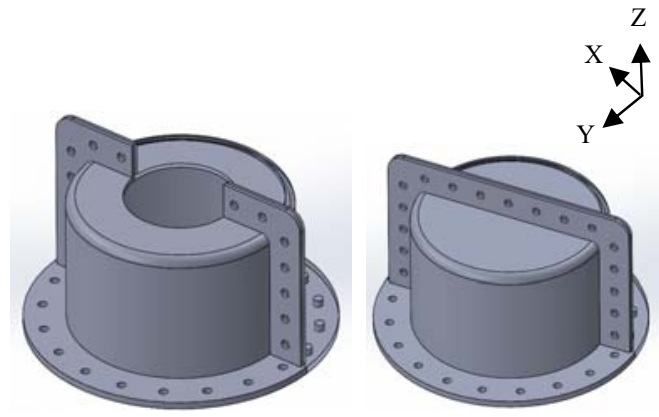

Gambar 4. Desain cetakan tabung gas komposit.

Flange dan head yang terhubung dengan valve atau katub dibuat dari material mild steel (MS) dengan gambar kerja pada Gambar 5 dan Gambar 6. Flange dan head dihubungkan dengan sistem baut, yaitu lima buah baut M5.

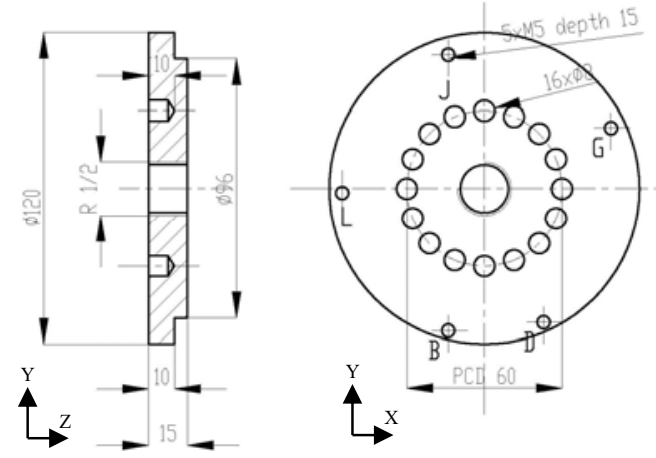

Gambar 5. Desain flange. 


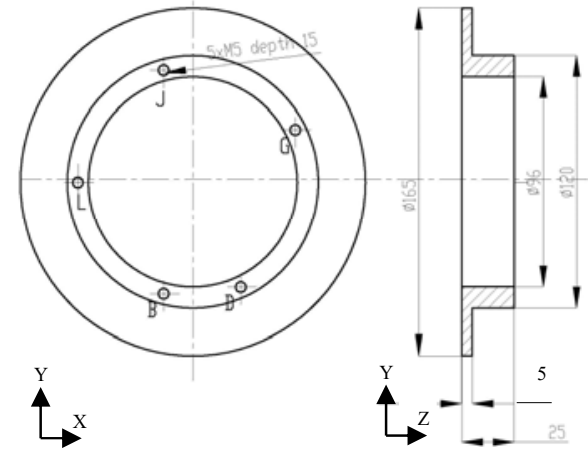

Gambar 6. Desain head.

Untuk desain dari bladder memiliki bentuk dan dimensi sama dengan dimensi tabung gas.

\section{Proses Manufaktur}

Proses manufaktur dimulai dengan membuat plug atau model untuk membuat cetakan. Plug dibuat dari material polyurethane foam tebal 50 mm yang dibentuk dengan proses bubut, dan disatukan antar layer dengan lem. Proses finishing permukaan menggunakan cat epoxy primer. Plug terdiri dari bagian atas dan bawah, serta diberikan sirip untuk pemisah sesuai dengan desain cetakan.

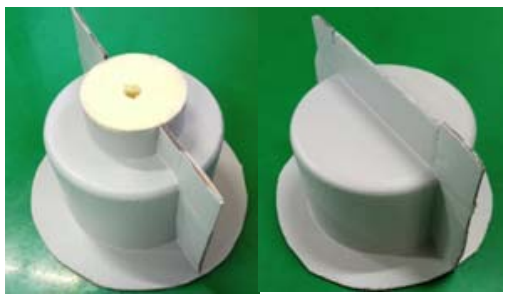

Gambar 7. Plug untuk membuat cetakan tabung gas komposit.

Cetakan tabung gas komposit dibuat dari material serat kaca jenis chopped strand mat dengan matriks resin epoxy tipe Bisphenol AEpichlorohydrin dan hardener EPH 555 tipe Cycloalipathic Anine dengan perbandingan 1:1. Cetakan dibuat sebanyak delapan lapisan dengan metode hand lay-up.

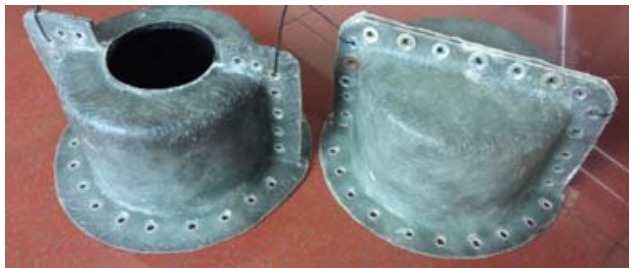

Gambar 8. Cetakan tabung gas komposit.

Flange dan head dibuat dengan proses turning $\mathrm{CNC}$ dan milling CNC. Untuk bladder dibuat dari latex dengan menggunakan cetakan bladder dan metode kuas.

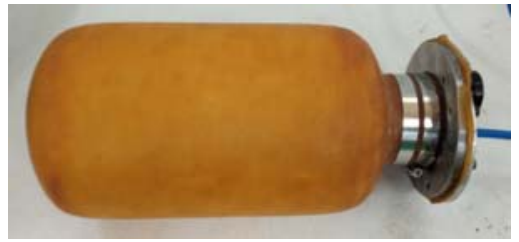

Gambar 9. Bladder atau kantung bertekanan.

Untuk pembuatan tabung gas komposit dimulai dengan pemotongan serat karbon sesuai dengan ukuran yang dibutuhkan. Pemotongan serat dibagi menjadi empat bagian, yaitu bagian dinding cetakan atas dan bawah sebanyak enam lapis, bagian head sebanyak 12 lapis, dan bagian cetakan bawah sebanyak delapan lapis. Selanjutnya cetakan dilapisi release mould dan lapisan gelcoat, dilanjutkan melapisi cetakan dengan serat karbon dan resin epoksi yang telah dicampur dengan hardener menggunakan metode hand lay-up. Setelah cetakan atas dilapisi sebanyak enam lapis, dilakukan pemasangan flange, kemudian dilapisi lagi dengan enam lapis serat karbon dan resin. Setelah semua cetakan terlapisi serat karbon dan resin, cetakan atas dan bawah disatukan. Kemudian bladder dimasukkan dan diberi tekanan sebesar 2 bar dan dilakukan proses curing selama 24 jam hingga material komposit mengeras dengan sempurna.

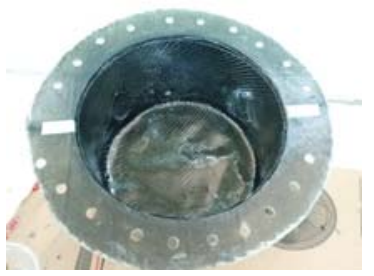

Gambar 10. Cetakan tabung gas komposit yang telah dilapisi serat karbon dan resin.

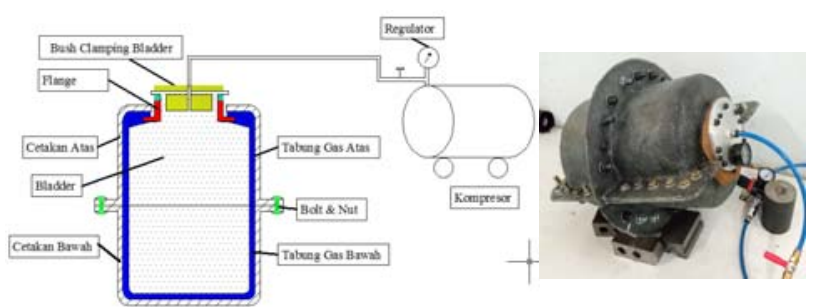

Gambar 11. Skema set up pembuatan tabung gas komposit.

\section{Proses Pengujian}

Pengujian tabung gas komposit dalam penelitian ini menggunakan uji hidrostatis. Uji ini merupakan tes untuk mengukur kekuatan suatu wadah atau bejana yang diberi tekanan (umumnya tekanan yang statis), serta melihat apakah terjadi kebocoran di dalam sistem tersebut. Fluida yang digunakan dalam uji hidrostatis adalah air. Tekanan 
dihasilkan oleh manual test pump, sedangkan tekanan kerja dapat dilihat pada pressure gauge.
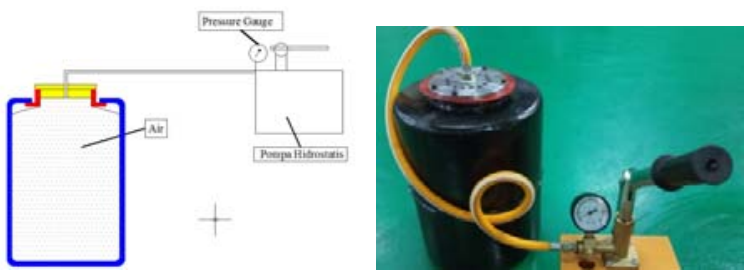

Gambar 12. Skema set up uji hidrostatis tabung gas komposit.

Pengujian dilakukan dengan memberikan tekanan secara bertahap, agar material tabung gas komposit mengalami stretching. Tekanan diberikan tiap 2 bar, dan ditunggu selama 5 menit sampai terjadi kebocoran pada tabung dan tekanan menurun yang dapat dilihat pada pressure gauge.

\section{HASIL DAN PEMBAHASAN}

Hasil spesifikasi tabung gas komposit yang dihasilkan adalah sebagai berikut:

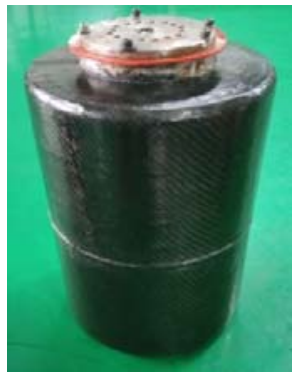

Gambar 13. Gambar produk tabung gas komposit serat karbon.

Hasil pengujian hidrostatis dengan manual test pump menunjukkan bahwa tabung dapat menerima tekanan hidrostatis hingga mencapai 18 bar. Pada saat tekanan sebesar 12 bar, setelah beberapa saat tekanan turun menjadi 11 bar dan stabil pada tekanan tersebut, tapi tidak terjadi kebocoran pada tabung gas komposit. Pada saat pengujian hidrostatis mencapai tekanan 14 bar, seperti ditunjukkan pada Gambar 14, terjadi suara gemeretak pada tabung komposit. Setelah beberapa saat tekanan turun menjadi 13 bar dan stabil pada tekanan tersebut, tetapi tidak terjadi kebocoran pada tabung gas komposit. Hal ini kemungkinan disebabkan karena material komposit mengalami stretching. Begitu pula pada saat pengujian hidrostatis mencapai tekanan 16 bar, terjadi suara gemeretak pada tabung komposit, tidak terjadi kebocoran, tetapi tidak terjadi penurunan tekanan. Pengujian dilanjutkan dengan menaikkan tekanan menjadi 18 bar dan setelah beberapa detik terjadi suara gemeretak yang cukup keras, hal ini diprediksi terjadi karena material mengalami over stretching dan berkurangnya kekuatan ikatan antar lapisan komposit. Setelah terjadi suara gemeretak yang cukup keras, terjadi kebocoran pada bagian radius bawah tabung gas komposit, seperti ditunjukkan pada Gambar 15 dan ditandai dengan penurunan tekanan secara cepat pada pressure gauge.

Terjadinya kebocoran pada bagian radius bawah tabung gas komposit diprediksi karena ikatan antar lapisan komposit pada bagian radius tersebut tidak sempurna. Hal ini kemungkinan terjadi pada saat proses penekanan material komposit dengan bladder, kantung bertekanan tersebut tidak bisa menjangkau bagian radius dengan maksimal sehingga berpengaruh pada kekuatan ikatan antar lapisan komposit. Hal ini dibuktikan dengan adanya rongga pada material komposit seperti ditunjukkan pada Gambar 15.

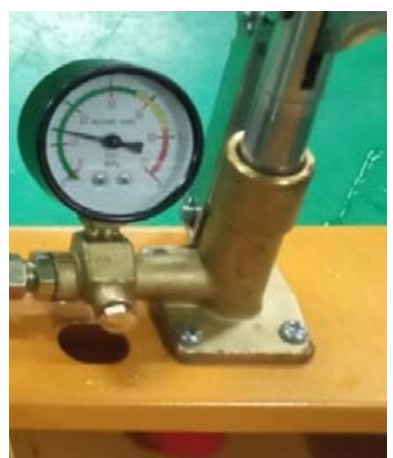

Gambar 14. Pembacaan pressure gauge saat pengujian tekanan hidrostatis 14 bar.

Tabel 2. Spesifikasi produk tabung gas komposit

\begin{tabular}{l|c|c}
\hline \multicolumn{1}{c|}{ Spesifikasi } & Requirements & Hasil Produk \\
\hline Tekanan pengujian & $15 \mathrm{bar}$ & $18 \mathrm{bar}$ \\
\hline Berat tabung & $<5 \mathrm{~kg}$ & $4 \mathrm{~kg}$ \\
\hline Kapasitas tabung & $>11$ liter & 12 liter \\
\hline Diameter tabung & $230 \mathrm{~mm}$ & $230 \mathrm{~mm}$ \\
\hline Tinggi tabung & $300 \mathrm{~mm}$ & $300 \mathrm{~mm}$ \\
\hline
\end{tabular}

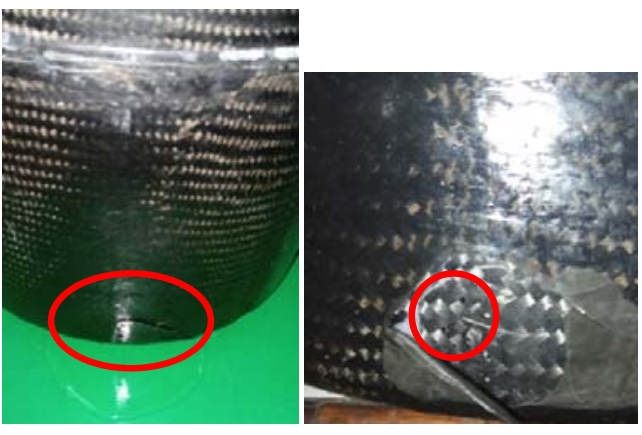

Gambar 15. Kerusakan akibat tekanan hidrostatits.

\section{KESIMPULAN}

Kesimpulan penelitian ini adalah:

1. Desain tabung gas komposit serat karbon dengan tekanan kerja 10 bar berhasil dibuat. 
2. Tabung gas komposit dengan material serat karbon jenis woven dengan matriks resin epoxy tipe Bisphenol A-Epichlorohydrin dan hardener EPH 555 tipe Cycloalipathic Anine berhasil dibuat dengan metode manufaktur komposit wet bladder compression moulding.

3. Tabung gas komposit serat karbon dapat menahan tekanan hidrostatis hingga 18 bar.

\section{DAFTAR PUSTAKA}

[1] Yi, X.S. and Du, S., 2018, Composite Materials Engineering, Volume 1 Fundamentals of Composite Materials, Springer Nature, Singapore.

[2] Badan Pusat Statistik, 2017, "Persentase Rumah Tangga Menurut Provinsi dan Bahan Bakar Utama untuk Memasak Tahun 2001, 2007-2016", https:/www.bps.go.id/statictable /2014/09/10/1364/persentase-rumah-tanggamenurut-provinsi-dan-bahan-bakar-utamauntuk-memasak-tahun-2001-2007-2016.html, diakses 25 Oktober 2020.

[3] Elmarakbi, A., 2014, Advanced Composite Materials for Automotive Applications: Structural Integrity and Crashworthiness, John Wiley \& Sons Ltd.

[4] Hakim, A.N., Sitinjak, P., and Rochman, T., 2015, "Rancang Bangun Tabung Komposit Tekanan Tinggi untuk Propelan Roket Cair Korosif “, Jurnal Teknologi Dirgantara 13 (2), pp.163-176.

[5] Nugroho, G., and Wantogia, M.S.R.R., 2019, "Proses Fabrikasi dan Sifat Mekanik Komposit Polimer dengan Metode Bladder Compression Moulding", Journal of Mechanical Design and Testing 1(2), pp. 95104.

[6] Anderson, J.P. and Altan, M.C., 2014, "Bladder Assisted Composite Manufacturing (BACM): Challenges and Opportunities". University of Oklahoma, Norman, USA.

[7] Direktur Jenderal Minyak Gas dan Bumi Kementrian Energi dan Sumber Daya Mineral Republik Indonesia, 2020, “Keputusan Direktur Jenderal Minyak Gas dan Bumi Kementrian Energi dan Sumber Daya Mineral Republik Indonesia Nomor 116.K/10/DJM/ 2020 tentang standar dan mutu (spesifikasi) bahan bakar gas jenis Liquefied Petroleum Gas yang dipasarkan di dalam negeri”.

[8] PT Blue Gas Indonesia, 2021, http://www.bluegaz.co.id/5/tabung-gas-t911.

[9] Megyesy, E.F., 1997, Pressure Vessel Handbook, $10^{\text {th }}$ Ed., Pressure Vessels Inc. 